La Revista de Filosofía de la Universidad de Chile, a través de estos estudios sobre el pensamiento de Jorge Millas, junto con rendir un homenaje al maestro al cumplirse cien años de su nacimiento, quisiera destacar la vigencia de su obra. Intentamos hacer este gesto de reconocimiento el año pasado, lo que habría sido más ajustado a dicha efemérides, pero, por distintas razones hemos debido aplazar esa iniciativa. Hemos completado ahora un expediente con tres estudios sobre el pensamiento de Millas; uno se refiere a su concepción del conocimiento (Alejandro Ramírez), otro sobre su ética (Raúl Villarroel) y el mío es sobre la idea de universidad en Jorge Millas. Junto con dedicar estos estudios a la memoria del querido maestro, en mi caso, lo hago también en descargo. Me parecía tener una deuda con Agustín Squella, filósofo del derecho también, como Millas, y editor suyo en este campo. En cierto momento, no pude sumarme a una iniciativa suya, que tenía por objeto, si mal no recuerdo, reunir un conjunto de trabajos sobre el pensamiento de Millas. Lo hago ahora -más vale así- con algún retardo.

\title{
DE LA UNIVERSIDAD COMPROMETIDA A LA UNIVERSIDAD VIGILADA
}

\author{
Marcos García de la Huerta \\ Universidad de Chile \\ marcos.garciadelahuerta@gmail.com
}

Yo sigo hablando de estas cosas en la esperanza de que antes que el daño sea mayor, las autoridades escuchen y recapaciten. Lo peor que puede ocurrirle a este pais, en horas tan aciagas, es que perdamos toda esperanza en el poder redentor del pensamiento (Agosto de 1982).

$\overline{R A}$ ¿Millas sería Millas si no hubiera resistido valientemente la intervención de las universidades durante la dictadura?

Es una pregunta hipotética, pues el caso es que resistió; y será recordado por ese acto de libertad que nunca le perdonaron sus adversarios y le hicieron pagar con su vida; siempre la política está tejida y entrelazada con el bios, por lo menos, el de la biografía. Que no hubiera resistido, sin embargo, es una posibilidad y una suposición similar a otra que algunos también han hecho: ¿Millas sería Millas si no hubiera sido filósofo? La respuesta que suele darse a esto es que habría sido poeta: lo afirman quienes admiran la elegancia y precisión de su castellano. Nicanor Parra, por ejemplo, contaba que Jorge Millas, Luis Oyarzún y él mismo, en su juventud, escribían solo poesía. Cuando el joven Millas viajó becado a Estados Unidos, en la universidad se habría iniciado en la filosofía analítica. "Lo sacaron al pizarrón a resolver ecuaciones y le secaron su vena poética", concluía Parra. 
¿Sería así o es la imaginación del poeta la que inventó este cuento? No parece verosímil, en todo caso, que una nueva filosofía fuera a hacer mella en una inteligencia cultivada como la suya, y forjada en el combate de las ideas: en el Kampfplatz filosófico. Es más probable que tomara la analítica del lenguaje como otro punto de vista, un nuevo método, que las otras filosofías no pueden dejar de tener en cuenta. Las ciencias, también las religiones, han estado enlazadas con la filosofía desde la antigüedad, y, lejos de ser un freno, han sido sus grandes estímulos. Y, en cuanto a que el adiestramiento en matemáticas fuera a sofocar la vena poética, tampoco resulta convincente, sobre todo en boca de un poeta y matemático. Me quedo, pues, con el juicio de Platón: "los poetas mienten mucho".

Pero la pregunta inicial tiene el propósito de poner aparte un aspecto de la vida y obra de Millas -sus intervenciones y pronunciamientos sobre la universidad-, para resaltar precisamente ese aspecto, no solo es el que le ha hecho más conocido, sino el que vincula su pensamiento con su experiencia y con su vida. Es decir, con su ética, si entendemos esta como práctica reflexiva de la libertad, como "el coraje de la verdad" -el título del último curso de Foucault, de 1984-, que puede ser también el nombre de la última lección que Millas nos dejó. Sus pronunciamientos sobre la universidad son ejercicios de pensamiento crítico, indisociables de su forma de vivir; en eso consiste su significación pública: no solo en la verdad de lo que él sostuvo sobre la Reforma y la función de la universidad, sino en la veracidad de su testimonio. Sus ideas y escritos más estudiados se refieren a temas de teoría: de filosofía del derecho, de epistemología, de historia de las ideas, pero ninguno comprometió tanto a Millas como sus pronunciamientos sobre la universidad. La mayor parte de sus libros, artículos, ponencias y pronunciamientos, dicho sea de paso, no ha sido reeditada en una versión completa. Es hora de hacerlo.

Nuestra intención, ahora, es hacer una semblanza del profesor y maestro que conocimos en clases y del intelectual público en que se convirtió, desde el momento en que se sintió llamado a salir en "defensa de la universidad": así se llama el libro que reúne sus intervenciones sobre el tema ${ }^{1}$. Y se trata de destacar, al mismo tiempo, que su actuación potenció esa "defensa"; luchó inicialmente contra la intrusión de la política en la academia, y más tarde, contra la intervención, en gran parte, llevado por la situación, pues, por carácter y vocación, era más bien remiso a la refriega. Si hay una constante en sus intervenciones, es, precisamente, su rechazo al predominio de la consigna sobre el "diálogo racional", y la necesidad de resguardar lo esencial de la universidad, que veía amenazada.

Mantenerse al margen en realidad se fue haciendo cada vez más imposible en el Chile de los sesenta, aunque se luchara, como él lo hizo, en su propio terreno y con sus propias armas: la pluma y la crítica. Solo en el memorable acto en el Teatro Caupolicán, intervino, junto con el expresidente Frei Montalva, con un discurso que revistió un carácter inequívocamente político, sobre todo por la situación en que se 
dio. Sus pronunciamientos "en defensa de la universidad", en efecto, son estrictamente académicos, realizados dentro de recintos universitarios y dirigidos a docentes y estudiantes. En ocasiones, también estaban presentes las nuevas autoridades, rectores designados o delegados, frente a los cuales Millas hacía su "defensa" con el único discurso posible: el de la libertad académica y la autonomía, o sea: autoridades elegidas por los propios académicos y no injerencia del poder político en las decisiones ¿Era ingenuo hacerlo ante rectores designados precisamente para intervenir? Era, en todo caso, una "ingenuidad" deliberada, estratégica y, por tanto, fingida. La ficción consistía en hacer como si el designado o delegado participara de la misma fuerza (relativa) y debilidad consustancial; consistía en hacer como si el designado o delegado respondiera a la misma lógica de la academia, como si no estuviera en la lógica interventora, en hacer como si el diálogo fuera posible; como si el otro fuera un interlocutor válido, en suma, como si la intervención fuera un disparate. ¿Era un diálogo de sordos? Ni siquiera eso: no hubo diálogo en absoluto ¿Había otra estrategia posible? Quizá, pero el caso es que ni siquiera esa la toleraron. Algunos de ellos no se cuidaban siquiera de dar una imagen distinta: recibían a los profesores en su despacho o se presentaban en los actos públicos, vestidos de uniforme, como para no dejar ninguna duda de por qué estaban allí. La única indumentaria que no llevaban, era el camuflaje y el armamento de combate.

"La fortaleza espiritual de que dio pruebas la universidad chilena en la hora del desafío, fue, en verdad, producto de su propia historia, confundida en su carácter democrático, con la historia de la nación" ". Estas palabras se refieren a la resistencia frente a un asedio: consiste en "cercarla por un anillo de suspicacia y vigilancia que comprometen seriamente su autonomía", y en "favorecer actitudes y crear condiciones adversas precisamente al espíritu que hizo posible reanimar la llama del pensamiento libre y reflexivo"3. Millas habla en participio pasado, a modo de advertencia, para indicar que no se había aprendido la lección, que seguíamos en la misma línea, en dirección inversa.

También aquí hay un juego de ficción; consiste en asimilar ambos momentos, el anterior y el posterior al eje divisorio de 1973 -que separa también las dos secciones del libro-, y hacer como si fueran equivalentes: hacer como si la amenaza fuera la misma, como si hubiera una simetría entre la intervención de ese momento (1976), y la intrusión y cooptación ideológica del pasado reciente. Millas habla desde uno de los dos púlpitos desde donde es posible hablar, y aun así lo acallaron.

Para que una institución, en principio pluralista y tolerante, se vuelva un campo de lucha, es preciso que un cierto número de factores haya vuelto incierto su ethos y haya perdido su funcionamiento acostumbrado. Cuando eso ocurre, ya no se percibe el futuro en relativa continuidad con el presente -y como proyección suya-, sino como una amenaza: se presiente la inminente, inevitable ruptura. Eso depende, claro está, 
de procesos sociales y políticos, pero se viven desde dentro de la academia como si desempeñaran solo un papel de incitación. Vale decir, que la política en la universidad parece que tuviera vida propia, y lo que se llama "intrusión" de la política en ella, es más reflejo y efecto de lo que ocurre afuera, que propiamente política universitaria. Esta diferencia es frágil y desapareció por completo con la intervención: terminó la necesaria ficción de la no política cuando la política entró a saco en los claustros: entró "la política con otros medios" - o con los suyos propios-, pero eso significa: desinstitucionalización.

Esto es lo que a Millas le resultó intolerable, pero advertía ya en la "superstición reformista" de fines de los años sesenta, la semilla de esta "intervención": veía el germen de la "intervención" en la "intrusión". Detectó en la universidad, como en un barómetro, el clivaje hacia "el derrumbe". "De hecho nuestra universidad va siendo progresivamente anquilosada en su espíritu y hasta ofendida en su dignidad. Uno de los poderes espirituales que la sociedad chilena necesita para arbitrar y frenar en alguna medida la lucha de intereses y las confrontaciones ideológicas, se halla así en vías de extinción. El proceso iniciado en la década del sesenta con ruido y aspavientos, bajo el signo de la izquierda, continúa hoy y se profundiza en silencio, bajo el signo de la derecha y otros signos. La nueva ley universitaria lo lleva a su término, institucionalizando las consecuencias más importantes y dejando indeterminadas muchas vías por donde podría profundizarse" 4 .

Todavía en 1976, decía: "Cuando en los peores momentos del asedio político a la universidad chilena, parecía sentirse el crujido anticipatorio del derrumbe, muchos nos asombrábamos de la resistencia con la que la institución retardaba el colapso final"5. Y remacha poco más adelante: "La universidad vigilada no es superior a la universidad comprometida"6.

En fecha muy temprana -febrero de 1968- protestaba contra el referéndum realizado en la Universidad de Chile sobre la normativa para un nuevo estatuto; sería un "acto despótico y falaz", "sin precedentes en su historia", afirma, por cuanto "fuerza a pronunciarse por meros detalles instrumentales, relativos a decisiones más profundas que se sustraen al veredicto" 7 . Se trata-agrega- de un "pseudo referéndum [que no contiene ni un solo] pronunciamiento sobre la nueva filosofía que se ha apoderado del movimiento de reforma. Ella se impone como artículo de fe que excomulga desde la partida a quienes puedan ponerla lealmente en duda" .

Delenda est universitas? En Idea y defensa de la universidad. Ediciones UDP, Santiago, 2012, pp. 170-171.

5 "Imperativo de confianza en la universidad chilena", op. cit., p. 97; también en diario El Mercurio, Santiago, 3 de enero de 1976.

Op. cit., p. 100.

Op. cit., p. 67 у 61.

Op. cit. p. 62. 
El más crítico de sus pronunciamientos reproduce en su título la expresión de un dirigente estudiantil de la época: Delenda est universitas? ¿Debe destruirse la universidad?). En esta misma Universidad dijo una vez un joven dirigente, con arrebato que a mí me pareció demoníaco, que el fin de las acciones que él encabezaba era 'destruir la Universidad' porque ahí comenzaba la demolición de la sociedad capitalista y la reconstrucción de la sociedad nueva"9.

¿Cita Millas estas palabras con la intención de analizarlas o discutirlas? No; las lee como un síntoma: lo "demoníaco" puede revestir formas pueriles, pero la puerilidad misma es un signo, y no siempre solo de estupidez. Afirmar que la muerte del capitalismo pasa por la destrucción de la universidad, ¿es absurdo? Quizá sea una obscenidad ontológica, pero esa obscenidad no está en la mente de Millas. Tampoco él diría: 'con semejantes críticos el capitalismo tiene su supervivencia asegurada'. Lo que está en liza no son las palabras del dirigente sino el clima intelectual y moral que las consiente, que las hace posibles y, hasta cierto punto, las autoriza aunque no las legitime. No se trataba de responder a la pregunta Qué hacer, sino de "qué hacer para mandar"10. Y agrega, con la misma benevolencia: "el comportamiento de los jóvenes no constituye un problema local de la universidad, sino de la sociedad chilena en su conjunto. En él se refleja la molicie de un ambiente colectivo que con diferentes pretextos y a menudo cínicamente, sin ellos, invita a la demolición de todos los valores" ${ }^{11}$.

Ya no estamos en medio de esa refriega, y podemos hacer una lectura sintomal de mucho de lo que entonces se decía y se hacía. Algunos tuvieron la sangre fría suficiente para hacerlo en vivo y en directo, por así decirlo; Lacan, por ejemplo, ante los estudiantes movilizados, los acogió con una sonrisa y unas sencillas palabras: "Lo que ustedes buscan es un amo. Lo tendrán"; un diagnóstico, mutatis mutandi, trágicamente profético.

En lugar de entrar en una discusión sobre el posicionamiento de Millas frente a la Reforma, parece más interesante ahora hacer esa lectura distanciada, porque su reserva frente a los acontecimientos es por sí misma, instructiva y aleccionadora. Él percibe un germen de desinstitucionalización en el asedio que comienza a experimentar la universidad en los sesenta, y que culmina con la intervención. Esta representa, para él, el perfeccionamiento de la des-institucionalización. Des-institucionalizar significa corromper, porque una institución se corrompe no solo cuando sirve intereses ajenos a aquellos para los que se creó sino cuando deriva en algo distinto de lo que es.

¿Qué es, pues, una universidad o qué no puede llegar a ser sin dejar de ser universidad? ¿Cuál sería su función propia?

$9 \quad$ En entrevista publicada por la Universidad Austral en 1977. Se encuentra también en internet. El pronunciamiento en referencia es Delenda est universitas? (¿Debe destruirse la universidad?) y es el capítulo final del libro Ideas y defensa de la universidad, op. cit., pp. 162ss.

10 Op. cit., p. 64

11 Op. cit., p. 69. 
Desde luego, "no puede dejar de ser una comunidad de maestros y discípulos destinada a la trasmisión y el progreso del saber" ${ }^{2}$. Es un "lugar, único tal vez en la sociedad, donde la gente se reúne sin otro propósito que el de saber cómo es y cómo ha sido el mundo -natural e histórico-, y cómo podemos saber todavía algo más sobre él y el de formar a los futuros ciudadanos en la capacidad de trabajo y con las expectativas de mejor vida humana que aquel saber permite"13. La universidad es también el último refugio del pensamiento libre, la única institución "donde, dadas las condiciones masivas de nuestra sociedad, se pueden salvar los valores del conocimiento y de la individualidad. Es el último refugio que en nuestra sociedad... puede encontrar el libre discernimiento" 14 .

Tres son los problemas fundamentales que enfrenta la universidad de nuestro tiempo, según Millas. Se puede hablar así, genéricamente, a pesar del "entrevero de tradiciones, magnitudes, prestigios, niveles de eficiencia, ideologías y doctrinas educacionales", porque habría cierta unidad, o ciertas tendencias comunes en las universidades actuales. El primer rasgo o tendencia es la "explosión demográfica" dentro de los claustros, es decir, "el hecho de que las universidades están llenas de gente: llenas de estudiantes, las aulas; de candidatos, las oficinas de matrícula; de profesores los claustros; de investigadores, los laboratorios; de empleados, las oficinas de administración”. Esto representa un primer gran desafío; pero: "la sociedad de masas ejerce una presión no solo demográfica sino espiritual" "15 "Un síntoma inequívoco de cuando una universidad se masifica, [es que] se interrumpe en ella el diálogo racional", es decir, "cuando ya no se respetan los miembros de esta comunidad; cuando ya no se reconoce el derecho a la divergencia; cuando el error de buena fe se convierte en estigma de traición y cuando se invita a la asonada, esto es, al automatismo de una conducta que funciona como un reflejo colectivo, y no como una acción personal" ${ }^{\text {"16 }}$. La intrusión de la política partidista en la universidad sofoca el "diálogo racional".

Cuando Millas habla de "masificación", se refiere al "hecho de las aglomeraciones" y al "hombre masa", según los caracterizó Ortega y Gasset; este fenómeno del lleno, "es bastante poderoso como para ser causa de lo que sucede en las universidades del mundo en cuanto a su tendencia a ser menos sabias y selectivas, menos claustrales y solemnes" ${ }^{17}$. Pero él se refiere también y sobre todo, sin nombrarla, a otra obra clásica sobre las masas: la Psicología de las masas. Freud señala allí, en la línea de Gustave Le Bon, que la conducta humana dentro de un colectivo tiende a perder la reflexividad propia de los actos conscientes individuales, y a volverse más propensa a responder

Op. cit., pp. 33-34.

Op. cit., p. 149, "Problemas fundamentales de la universidad contemporánea".

Op. cit., p. 43.

Op. cit., p. 156.

Op. cit., p. 42.

Op. cit., p. 138. 
a la afectividad y al deseo; sería, pues, una conducta más vulnerable a las promesas y consignas ideológicas, más remisa al "diálogo racional"18.

Un segundo problema de la universidad actual lo constituye "el hecho del crecimiento acelerado del conocimiento científico del mundo y de la preeminencia que en la vida del hombre ha llegado a tener el poderío tecnológico aparejado a ese conocimiento". Esto constituye otro gran desafío: "La sociedad de nuestro tiempo va siendo por ritmo de aceleración cada vez más acelerada, una sociedad técnica de masas... La vida humana se ha hecho función dependiente del desarrollo técnico"19.

El tercer punto es "el lugar que, querámoslo o no, ocupa la ciencia en el ambiente de nuestras vidas". Es un hecho de sobra conocido, pero es de la mayor importancia, porque la universidad es la institución social que se han dado las sociedades para la trasmisión del saber superior, es decir, que la universidad tiene un vínculo y asociación entrañable con la ciencia. ¿Y con su creación? No siempre la universidad ha sido el lugar único o exclusivo de la creación de la ciencia. La ciencia espacial, por ejemplo, actualmente se desarrolla de consuno con la exploración espacial y, al menos en Norteamérica, aunque resulte sorprendente a nuestra mirada terrícola, la empresa privada invierte sumas siderales, valga la redundancia, en explorar Marte y el espacio exterior. Los observatorios astronómicos con sus mega-telescopios no son de carácter universitario, por una razón análoga: no hay presupuesto universitario que resista eso. Los primeros científicos modernos, como Descartes, Espinoza o Leibniz, no realizaron sus investigaciones dentro de una universidad; lo mismo puede afirmarse de Pascal, Hume, Locke o Voltaire. No siempre las nuevas ideas y los nuevos inventos surgieron en el marco de cátedras universitarias, y a veces fue al revés: la academia obstaculizó el avance del saber ${ }^{20}$.

Hoy la situación es distinta, claro está. La época en la que un hombre de ciencia solitario, disponiendo de medios artesanales, y premunido tan solo de su ingenio e inteligencia, podía realizar grandes descubrimientos, ya pasó. Pero ahora existe el riesgo inverso, y es que la ciencia y el saber derivado de ella abarquen y consuman todo el esfuerzo de las academias. Ante eso, es preciso afirmar que "la universidad es distinta pero inseparable de la ciencia. Yo diría es, además, ciencia"21. En otras palabras, la universidad no puede existir sin ciencia, pero no puede convertirse en una institución solo científica (o solo tecnológica o solo profesional).

Habría, en síntesis, una idea central en esta "defensa de la universidad". En realidad, es una idea -la del asedio- con variantes estratégicas: primero se expresa en la intrusión ideológica, luego en la intervención directa, que representa una redefinición institucional, porque, a la postre, la intervención significó "privatización", es decir, autofinanciamiento, crédito fiscal o bancario para los estudiantes, etc. Millas escribe,

18 Sigmund Freud, Psicología de las masas.

19 Op. cit., p. 38.

20 Op. cit., p. 143.

${ }^{21}$ Op. cit., p. 120. Millas cita aquí a Ortega y Gasset, Misión de la universidad. 
en 1981: "La tesis fundamental de este libro [es] la continuidad en el deterioro creciente de la universidad chilena a lo largo de los últimos quince años"22. "Ya hoy, como resultado de la eliminación de centenares de académicos experimentados, se acentúa la mediocridad" 23 .

Este diagnóstico se complica con juicios que ahora parecen un tanto anacrónicos: "La peor perspectiva en que puede colocarse a las universidades para entender su misión, resolver sus problemas y promover su desarrollo, es la de la sociedad de consumo y de la economía social de mercado" 24 . Habría que precisar, que no todas las universidades están obligadas a seguir el mismo canon o matriz, es decir, que en "la sociedad de consumo" subsisten universidades creadas en plena Edad Media. El lema sesentero de "universidad para todos" difícilmente habría podido cumplirse en el marco del sistema entonces vigente.

Para refrendar la idea de un "progresivo anquilosamiento", Millas trae a la memoria un dato bien conocido, aunque olvidado: "La Universidad de Chile -para tomar uno entre varios ejemplos- necesitó solo un rector para inspirar y dirigir la expansión y modernización ocurridas entre 1932 y 1953 ... Lo sucedió otro académico, también elegido y reelegido por un período total de diez años... bajo cuyo impulso tuvo lugar una readecuación notable de la investigación científica en la universidad". Se refiere, claro está, a los rectorados de Juvenal Hernández y de Juan Gómez Millas; "el balance es impresionante. En 30 años de administración autónoma la Universidad de Chile tuvo dos rectores. En 8 años de administración intervenida ha necesitado seis, y el último acaba de emprender nuevas "reestructuraciones" 25 . Parece indispensable hacer aquí una precisión. Se trata, en efecto, de épocas muy distintas; la Universidad de Chile recibía del Estado en aquel tiempo, el 2\% del Presupuesto Nacional, garantizado por disposición constitucional. Pensar que eso volverá a ocurrir sería soñar, entre otras razones, porque, entretanto, se han consolidado muchas universidades privadas, que pueden exhibir realizaciones innegables, la más importante, quizá: la ampliación sustantiva de la cobertura: las matrículas de hoy más que decuplican las de entonces. La Universidad de Chile, aunque sigue siendo la más importante y la que puede llamarse "nacional", ya no es, por así decirlo, la estrella de la bandera que alguna vez intentó ser y, hasta cierto punto, lo fue.

Esto no debilita, sin embargo, el argumento central. La cuestión Qué es una universidad, mantiene vigencia y es un faro orientador: la universidad es tal cosa y tal otra; no puede dejar de ser eso sin dejar de ser universidad. Es preciso exigir que se cumplan esos estándares, de otro modo, se corrompe la universidad, se desinstitucionaliza, sigue el curso enigmáticamente sincrónico, que siguen varias otras instituciones que nadie duda, son esenciales e indispensables.

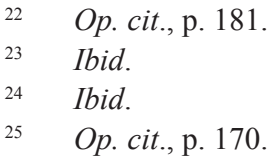

